\title{
Evaluation of adherence to chronic obstructive pulmonary disease prescribing guidelines- A single centre study
}

\author{
Viviane Khalil ${ }^{1,2 *}$, Amanda (Qiantong) Hua ${ }^{1}$ and Skip Lam ${ }^{1}$ \\ ${ }^{1}$ Pharmacy Department Peninsula Health, Australia \\ ${ }^{2}$ Monash University, Australia
}

\begin{abstract}
Introduction: Chronic obstructive pulmonary disease (COPD) is a worldwide health problem. Evidence suggests that the management of COPD patients is substandard when compared to treatment guidelines.

Methods: A retrospective cross-sectional audit of patients admitted over 12-months for management of exacerbations of COPD (ICD-M120) was conducted in an Australian hospital. Data collected included patients' demographics, co-morbidities, admitting team, COPD-related medications on admissions and discharge, and spirometry data. The primary aim of this study was to evaluate the proportion of patients who were prescribed evidence-based COPD therapy on discharge compared to admission. The secondary aims were to evaluate adherence of the respiratory team to prescribing guidelines compared to general medical teams as well as assessing factors for prescribing compliance.

Results: A total of 274 patients were eligible to be included. On discharge, the percentage of appropriate therapy increased from $44 \%$ to $53 \%$ compared to that on admission, $\mathrm{p}<0.01$. A slightly higher percentage of patients $(56 \%)$ were discharged on recommended therapy when managed by respiratory teams compared to non-specialised teams $(50 \%), \mathrm{p}=0.389$. Patients who had asthma or previous exacerbations of COPD were more likely to receive optimum treatment; $\mathrm{OR}=9.444$ 95\%CI (1.982-44.998) and $\mathrm{OR}=2.940(1.706-5.068), \mathrm{p}<0.01$ respectively.

Conclusion: This study identified gaps in the management of COPD patients in this tertiary setting. A better compliance to prescribing guidelines was observed among respiratory specialists. Patients with a history of asthma and/or multiple exacerbation of COPD were more likely to be optimally treated in this study. Improving awareness of COPD guidelines is vital for patients' management.
\end{abstract}

\section{Introduction}

Chronic obstructive pulmonary disease (COPD) is a worldwide health problem with major social and economic impact [1]. COPD is a significant cause of disease burden and mortality in Australia [2]. COPD is also associated with substantial health and economic burden worldwide and the prevalence of COPD is increasing due to the aging population and continued exposure of the population to risk factors [3].

Current evidence suggests that the management of COPD patients is substandard, with evidence of over-treatment and under-treatment, when compared to current guidelines such as the COPD-X guidelines (used in Australia and New Zealand) and the GOLD guidelines [1,4-9]. The COPD-X guidelines used in Australia classify the severity of COPD based on spirometry assessment into three categories to guide medical management; mild $\left(\mathrm{FEV}_{1} \approx 60-80 \%\right.$ predicted $)$, moderate $\left(\mathrm{FEV}_{1} \approx\right.$ $40-59 \%$ predicted $)$ and severe $\left(\mathrm{FEV}_{1}<40 \%\right.$ predicted $)$ [1]. There is great importance in appropriately managing COPD treatment as inappropriate prescribing of medications could increase the financial burden on the healthcare system and worsen patient outcomes [4].

Data assessing concordance of management of COPD patients in hospitals with clinical guidelines is sparse [10,11]. Given the economic and health burden on our society, it is important to examine our local practice for managing inpatients admitted for exacerbations of COPD with the aim to optimise their medical management. It has been suggested that pulmonary specialists may follow national guidelines more closely than general physicians in the management of patients with COPD $[10,11]$. However these findings need to be confirmed by further studies.

The primary aim of this study was to evaluate the proportion of patients prescribed evidence-based maintenance therapy of COPD according to the COPD-X guidelines on discharge at this hospital compared to admission. The secondary aims were to compare the rate of guideline adherence between the respiratory teams and nonspecialized medical teams and assess patients' factors affecting their COPD management.

\section{Method}

A retrospective cross-sectional audit of medical records was conducted on patients admitted for management of exacerbations of COPD (ICD-M120) in a large Australian metropolitan hospital from January 2016 to February 2017. The inclusion criteria are: patients $>18$ years of age with confirmed diagnosis of COPD by spirometry within

${ }^{\star}$ Correspondence to: Viviane Khalil, Pharmacy Department Peninsula Health Frankston, Melbourne, Hasting Rd, Peninsula Health, Vic 3199 Australia, Tel: +613 9784 7602, E-mail: vkhalil@phcn.vic.gov.au

Received: July 10, 2019; Accepted: July 27, 2019; Published: July 30, 2019 
12 months prior to admission or 3 months post admission. Exclusion criteria included any patients with no spirometry data, incomplete medical record, diagnosis of other pulmonary diseases other than COPD based on spirometry results (i.e. $\mathrm{FEV}_{1} / \mathrm{FVC}>70 \%$ ) and patients transferred from or to a rehabilitation hospital due to incomplete episode of care. Palliated or deceased patients were also excluded from the study. Ethics approval was obtained from the Research and Ethics Committee of the institution (Approval number QA/16/PH/34).

The prescribing of COPD therapies on discharge was compared against the recommendations of the COPD-X guidelines, which were considered appropriate given they have been adapted by local clinicians [1]. All patient records were independently assessed by two authors (VK, AH) and disagreement was resolved through re-evaluation and discussion. Patient factors such as severity of COPD using predicted $\mathrm{FEV}_{1}$ and the presence or absence of relevant co-morbidities such as asthma were taken in account consistently by the two authors during the assessment process.

Appropriateness of drug treatment was established in accordance with the 2017 COPD-X guidelines ${ }^{1}$ recommendations as below:

1. In mild COPD, it is recommended to add a short-acting bronchodilator when needed and consideration to regular treatment of one or more long-acting bronchodilator (long-acting $\mathrm{B}_{2}$-agonist [LABA] and/or long-acting muscarinic antagonist [LAMA]) for symptom relief.

2. In moderate COPD, the guidelines recommend adding regular treatment with one or more long-acting bronchodilator (LABA and/ or LAMA) and consideration to adding ICS for those with $\mathrm{FEV}_{1}<50 \%$ predicted and 1 or more exacerbations in the previous 12 months.

3. In severe COPD, addition of a regular treatment with one or more long-acting bronchodilator (LABA and/or LAMA) and consideration adding ICS for those with $\mathrm{FEV}_{1}<50 \%$ predicted and 2 or more exacerbations in the previous 12 months are recommended. Low dose theophylline could also be considered.

A patient was considered to be under-treated if there was a lack of appropriate inhalers given their severity of COPD (eg. not on LABA or LAMA when COPD severity was moderate to severe). A patient was considered over-treated if there were inappropriate treatment (eg. on ICS/LABA combination therapy when COPD severity was mild).

Audit data were collected by two clinical pharmacists. Data collected from medical histories included patient demographics, comorbidities, admitting team, COPD related medications on admission and discharge, spirometry data, and length of stay. Data was entered into Excel 2007 (Microsoft Corporation, Redmond, WA, USA) where it was analysed and compared. Analysis of data involved both descriptive, univariate, and multivariate statistics. Data were analysed using SPSS, version 24.0 (SPSS, Inc, an IBM Company, Chicago, Illinois).

Descriptive statistics were used to summarise patient demographics and management. Chi squared test was used to examine the univariate relationship between each set of categorical variables. A significance level of $\mathrm{p}<0.05$ was considered statistically significant for all tests. Multiple logistic regression model was used to examine the relationship between the independent variables such as gender, age, presence of comorbidities, admission team (respiratory or medical) and the dependent variables which were appropriateness of treatment according to the COPDX guidelines (optimum treatment, under- or over-treatment). The results are presented in adjusted odds ratios (OR) with $95 \%$ confidence intervals ( $95 \% \mathrm{CI})$.

\section{Results}

Over the study period, there was a total of 1031 admissions in this metropolitan hospital with a primary diagnosis of exacerbation of COPD. A total of 274 admissions fulfilled the inclusion criteria and were eligible to be included in the study. The mean age $( \pm S D)$ of patients included in the study was $71.8( \pm 10.5)$ years with mean predicted $\mathrm{FEV}_{1}$ $( \pm$ SD) of $49.2 \%( \pm 20.9)$. Half the patients who were included in the study were males. The mean length of stay $( \pm \mathrm{SD})$ was $5.3( \pm 5.1)$ days. Hypertension, ischemic heart disease and chronic kidney disease were the three most prevalent co-morbidities in the examined cohort ( $48 \%, 24 \%$ and $19 \%$ respectively). According to the COPD-X guideline classification, $41 \%(n=112)$ of patients had severe COPD, 29\% $(n=79)$ had moderate COPD and 30\% $(n=83)$ had mild COPD (Table 1$)$.

On admission, $44 \%(n=120)$ of patients were already on appropriate inhaler therapy according to COPD-X guidelines; $9 \%(n=25)$ were under-treated while $47 \%(n=129)$ were over-treated upon presentation to hospital. The percentage of appropriate therapy increased from $44 \%$ on admission to $53 \%$ on discharge $(\mathrm{p}<0.01)$; and the percentage of patients who were classified as either undertreated or overtreated was reduced from $56 \%$ to $47 \%(\mathrm{p}<0.01)$ after therapy adjustment in the hospital.

Patients in this study were either managed by the respiratory (specialised) team or the non-specialised teams. The respiratory team admitted $49 \%(n=135)$ of all audited patients. Univariate analysis of the data showed a slightly higher percentage of patients $(56 \%, n=75)$ were discharged on recommended therapy according to COPD-X guidelines when managed by the respiratory team compared to the non-specialised teams $(50 \%, \mathrm{n}=70)$; however the results did not reach statistical significance $(\mathrm{P}=0.389)$ (Table 2$)$.

Patients with mild COPD ( $\mathrm{n}=83)$, a total of $43 \%(\mathrm{n}=36)$ were treated optimally, $10 \%(n=8)$ were under-treated and $47 \%(n=39)$ were over-treated. In patients with moderate COPD $(n=79), 57 \%(n=45)$ received optimal treatment, $11 \%(\mathrm{n}=9)$ were under-treated and $32 \%$ $(\mathrm{n}=25)$ were over-treated. In patients with severe COPD $(\mathrm{n}=112), 57 \%$ $(\mathrm{n}=64)$ had optimal treatment, $17 \%(\mathrm{n}=19)$ were under-treated and $26 \%(n=29)$ were over-treated (Figure 1$)$.

The predictors of appropriateness of COPD management were sought using multiple regression analysis as presented in Table 3. Patients with a past history of asthma or previous COPD exacerbations that required hospital exacerbations were more likely to be treated

Stratification of management of COPD patients on discharge by disease severity and by team

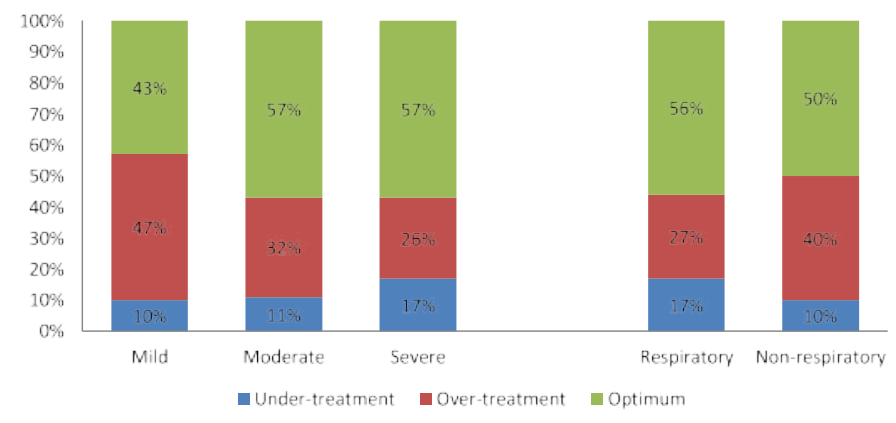

Figure 1. Percentage of patients in each treatment classification per COPD severity class and by treating team

Patients included in this cross-sectional audit were stratified according to COPD disease severity and the treating team. The proportion of patients prescribed optimal or suboptimal COPD treatment are presented graphically for each strata. 
Table 1. Patients' characteristics included in the study

\begin{tabular}{|c|c|}
\hline Patients' Demographics & $\begin{array}{c}\mathrm{n}=274 \\
\mathrm{n}(\%)\end{array}$ \\
\hline Male & $136(50 \%)$ \\
\hline Mean age (SD) (years) & $72( \pm 10)$ \\
\hline Respiratory team admission & $135(49 \%)$ \\
\hline Hospital admissions for COPD in last 12 months & $122(45 \%)$ \\
\hline Current smoker & $93(34 \%)$ \\
\hline Ex-smoker & $172(63 \%)$ \\
\hline Never smoked & $2(1 \%)$ \\
\hline Smoking history Not reported & $7(2 \%)$ \\
\hline Mean Smoking history (SD) (Pack year) & $47( \pm 35)$ \\
\hline Mean predicted $\mathrm{FEV}_{1}(\mathrm{SD})$ & $49( \pm 21)$ \\
\hline Mean $\mathrm{FEV}_{1} / \mathrm{FVC}(\mathrm{SD})$ & $47( \pm 16)$ \\
\hline Mean LOS (SD) (days) & $5( \pm 5)$ \\
\hline \multicolumn{2}{|l|}{ Comorbidities } \\
\hline Hypertension & $131(48 \%)$ \\
\hline Ischaemic heart disease & $67(24 \%)$ \\
\hline Chronic kidney disease & $51(19 \%)$ \\
\hline Hyperlipidaemia & $50(18 \%)$ \\
\hline Diabetes mellitus & $48(17 \%)$ \\
\hline Heart failure & $43(16 \%)$ \\
\hline Depression & $39(14 \%)$ \\
\hline Atrial fibrillation & $18(7 \%)$ \\
\hline Asthma & $18(7 \%)$ \\
\hline Lung malignancy & $14(5 \%)$ \\
\hline
\end{tabular}

Table 2. Stratification of patients according to COPD-X per admitting team

\begin{tabular}{|c|c|c|c|}
\hline $\begin{array}{l}\text { Total } \\
n=274\end{array}$ & $\begin{array}{c}\text { Optimum } \\
n=145\end{array}$ & $\begin{array}{c}\text { Under } \\
\text { Treated } \\
\mathbf{n}=\mathbf{3 6}\end{array}$ & $\begin{array}{c}\begin{array}{c}\text { Over } \\
\text { Treated } \\
\mathbf{n}=93\end{array} \\
\end{array}$ \\
\hline Respiratory team $(n=135)$ & $\begin{array}{c}56 \% \\
(\mathrm{n}=75)\end{array}$ & $\begin{array}{c}17 \% \\
(\mathrm{n}=23)\end{array}$ & $\begin{array}{c}27 \% \\
(\mathrm{n}=37)\end{array}$ \\
\hline General Medical \& other teams $(n=139)$ & $\begin{array}{c}50 \% \\
(n=70)\end{array}$ & $\begin{array}{c}10 \% \\
(n=13)\end{array}$ & $\begin{array}{c}40 \% \\
(n=56)\end{array}$ \\
\hline $\mathbf{X}^{2}$ & 0.742 & 3.544 & 5.068 \\
\hline$P$ value & $\mathrm{P}=0.389$ & $\mathrm{P}=0.600$ & $\mathrm{P}=0.024$ \\
\hline
\end{tabular}

Table 3. Multiple logistic regression of variables association with optimal treatment, under-treatment or over-treatment

\begin{tabular}{|c|c|c|c|c|c|c|}
\hline & $\begin{array}{l}\text { Optimum Treatment } \\
\text { OR }(95 \% \mathrm{CI})\end{array}$ & P Value & $\begin{array}{l}\text { Over treatment OR } \\
(95 \% \mathrm{CI})\end{array}$ & P Value & $\begin{array}{c}\text { Under Treatment OR } \\
(95 \% \mathrm{CI})\end{array}$ & P Value \\
\hline Male gender & $\begin{array}{c}1.078 \\
(0.628-1.850)\end{array}$ & 0.785 & $\begin{array}{c}0.680 \\
(0.373-1.242)\end{array}$ & 0.210 & $\begin{array}{c}1.698 \\
(0.765-3.769)\end{array}$ & 0.193 \\
\hline Older age & $\begin{array}{c}1.237 \\
(0.637-2.403)\end{array}$ & 0.530 & $\begin{array}{c}0.748 \\
(0.351-1.598)\end{array}$ & 0.454 & $\begin{array}{c}0.991 \\
(0.411-2.387)\end{array}$ & 0.983 \\
\hline Respiratory team & $\begin{array}{c}1.232 \\
(0.699-2.171)\end{array}$ & 0.470 & $\begin{array}{c}0.485^{*} \\
(0.258-0.913)\end{array}$ & 0.025 & $\begin{array}{c}2.299 \\
(0.997-5.302)\end{array}$ & 0.051 \\
\hline Ex-smoker & $\begin{array}{c}0.929 \\
(0.536-1.609)\end{array}$ & 0.793 & $\begin{array}{c}1.114 \\
(0.604-2.057)\end{array}$ & 0.729 & $\begin{array}{c}0.953 \\
(0.436-2.082)\end{array}$ & 0.904 \\
\hline Length of stay & $\begin{array}{c}1.070 \\
(0.611-1.874)\end{array}$ & 0.812 & $\begin{array}{c}1.040 \\
(0.556-1.944)\end{array}$ & 0.902 & $\begin{array}{c}0.797 \\
(0.349-1.820)\end{array}$ & 0.590 \\
\hline $\begin{array}{l}\text { Exacerbation that required hospital } \\
\text { admission in the last } 12 \text { months }\end{array}$ & $\begin{array}{c}2.940 * * \\
(1.706-5.068)\end{array}$ & 0.001 & $\begin{array}{c}0.140 * * \\
(0.072-0.273)\end{array}$ & 0.001 & $\begin{array}{c}2.880 * * \\
(1.300-6.379)\end{array}$ & 0.009 \\
\hline Mild COPD & $\begin{array}{c}0.617 \\
(0.312-1.221)\end{array}$ & 0.165 & $\begin{array}{c}1.812 \\
(0.866-3.788)\end{array}$ & 0.114 & $\begin{array}{c}0.997 \\
(0.367-2.710)\end{array}$ & 0.995 \\
\hline Moderate COPD & $\begin{array}{c}1.058 \\
(0.538-2.079)\end{array}$ & 0.871 & $\begin{array}{c}1.003 \\
(0.468-2.149)\end{array}$ & 0.993 & $\begin{array}{c}1.063 \\
(0.397-2.848)\end{array}$ & 0.903 \\
\hline History of Cardiovascular disease & $\begin{array}{c}0.793 \\
(0.428-1.467)\end{array}$ & 0.460 & $\begin{array}{c}1.053 \\
(0.534-2.075)\end{array}$ & 0.881 & $\begin{array}{c}1.361 \\
(0.557-3.325)\end{array}$ & 0.499 \\
\hline History of Lung Malignancy & $\begin{array}{c}0.736 \\
(0.211-2.560)\end{array}$ & 0.629 & $\begin{array}{c}0.764 \\
(0.183-3.194)\end{array}$ & 0.712 & $\begin{array}{c}2.391 \\
(0.548-10.428)\end{array}$ & 0.246 \\
\hline History of Chronic Kidney Disease & $\begin{array}{c}1.470 \\
(0.731-2.956)\end{array}$ & 0.280 & $\begin{array}{c}0.811 \\
(0.366-1.796)\end{array}$ & 0.606 & $\begin{array}{c}0.683 \\
(0.235-1.983)\end{array}$ & 0.483 \\
\hline History of Depression & $\begin{array}{c}1.718 \\
(0.803-3.674)\end{array}$ & 0.163 & $\begin{array}{c}0.487 \\
(0.200-1.185)\end{array}$ & 0.113 & $\begin{array}{c}1.096 \\
(0.378-3.178)\end{array}$ & 0.867 \\
\hline History of Asthma & $\begin{array}{c}9.444 * * \\
(1.982-44.998)\end{array}$ & 0.005 & $\begin{array}{c}0.095^{*} \\
(0.011-0.796)\end{array}$ & 0.030 & $\begin{array}{c}0.330 \\
(0.040-2.716)\end{array}$ & 0.303 \\
\hline
\end{tabular}

$\mathrm{p}<0.05^{*}$ and $\mathrm{P}<0.01 * *$ 
optimally; $\mathrm{OR}=2.94095 \% \mathrm{CI}(1.706-5.068)$ and $\mathrm{OR}=9.44495 \% \mathrm{CI}(1.982$ 44.998), $\mathrm{P}<0.01$ respectively.

\section{Discussion}

This audit reflects the treatment patterns of maintenance COPD therapy in a metropolitan Australian hospital through examining adherence to treatment recommendations of COPD-X guideline. The mean age of our cohort was 71.8 years, which is similar to the mean age of the COPD population examined in other COPD audits [5,9]. There was an approximately equal proportion of males and females in our sample; this is expected due to the similar prevalence of COPD between males and females in Australia [12]. The mean length of stay was 5.3 days which correlated well with a national average length of stay of 5.7 days in Australia for 2015-16 [13]. The proportion of patients who are current smokers in our study cohort is rather high (34\%). Similar prevalence of cigarette smoking was found in other cohort studies indicating smoking cessation is one of the most important interventions for patients admitted to hospital with COPD exacerbations $[5,9]$.

The COPD-X guideline 2017 acknowledges the importance of management of COPD therapy in the primary-care setting to optimize lung function, prevent deteriorations and exacerbations. However our findings show that only $44 \%$ of patients were on appropriate inhaler therapy prior to admission to hospital, indicating that COPD is often not managed in primary care according to the most recent COPD guidelines [1].

During management of COPD exacerbations in the hospital setting, an opportunity arises for physicians to review patients' inhaled therapy according to their clinical needs. The proportion of patients on appropriate inhalers according to the COPDX guideline was 53\% upon discharge (significantly increased from $44 \%$ on admission, $\mathrm{P}<0.05$ ). The results highlight that hospital admission provides an opportunity for physicians to re-assess and adjust therapy in patients admitted to hospital for COPD exacerbations to optimise their management. There were only a small proportion of patients undertreated in our cohort either on admission or discharge ( $9 \%$ vs $13 \%$ respectively). The most common reason of under-treatment was the lack of prescribing longacting bronchodilators (LAMA or LABA) in patients with moderatesevere COPD where there is no contraindication to therapy. The lack of prescribing a SABA or SAMA on discharge was also counted as under-treatment which was documented in a number of cases across all COPD severity classes.

In our study, $34 \%$ of examined patients were over-treated on discharge according to the COPD-X guideline. ${ }^{1}$ Over prescribing of ICS in patients who do not meet the specified COPD-X criteria (ie. $\mathrm{FEV}_{1}<50 \%$ and 1 or more exacerbations in the last 12 months) was the most common reason of over-treatment. Co-prescribing of both LAMA and SAMA was also observed and classified as over-treatment because COPD-X guideline recommends that SAMA should be discontinued once a LAMA is commenced.

Patients who had repeated COPD exacerbations requiring hospital admission in the last 12 months were three times more likely to receive optimal treatment on discharge $(\mathrm{OR}=2.940,95 \% \mathrm{CI}(1.706-5.068)$, $\mathrm{p}<0.01)$. They were also less likely to be over-treated $(\mathrm{OR}=0.140$, 95\%CI $(0.072-0.273) \mathrm{p}<0.01)$. Similarly, White et al. reported overtreatment was less likely in patients who reported an exacerbation requiring oral steroids or a hospital admission for COPD [4]. This subgroup of patients was those who will benefit from combination ICS therapy according to COPD-X guidelines. These findings reflect that patients with repeated COPD exacerbations were well managed with the indicated therapy and much less likely to be over-treated.

A history of asthma was another strong predictor of optimal COPD therapy on discharge ( $\mathrm{OR}=9.44,95 \% \mathrm{CI}(1.982-44.998), \mathrm{p}<0.01)$. ICS is indicated in patients with overlap phenotype of asthma and COPD. The result suggests patients with overlapping asthma and COPD diagnosis are likely to be prescribed indicated therapy including ICS to manage their inflammatory condition.

In our results, as the severity of COPD increased, the proportion of patients receiving optimal inhaled therapy on discharge also increased. The COPD-X guideline recommends a stepwise approach in the prescribing of maintenance COPD therapy according to the severity of airflow limitation (based on $\mathrm{FEV}_{1}$ ). Therefore, the higher percentage of optimal therapy in moderate-severe COPD is likely due to qualified use of combination bronchodilators with ICS. Conversely, patients with mild COPD did not qualify for combination ICS therapy due to $\mathrm{FEV}_{1}>50 \%$, this was the most likely explanation for the higher rate of over-treatment observed in this subgroup of patients.

Over-treatment of COPD with inhaled corticosteroid has been reported in numerous studies [4,14-16]. A cross-sectional study conducted in the UK by White et al reported $38 \%$ of the patients were over-treated according to GOLD 2009 guidelines and in $96 \%$ of these cases over-treatment was with ICS. ${ }^{4}$ Sen et al. also found substantial proportion of over-treatment of COPD in early stages and high rate of ICS use (89\%) in all stages of disease resulted in improper treatment according to GOLD 2010 recommendations (14). Similar result of over-treatment was observed in our audit even though local Australian COPD-X guidelines were used instead of the GOLD guideline. This suggests the widespread issue of inappropriate ICS use irrespective of the region and minor guidelines differences. Inappropriate use of ICS in patients with COPD needs to be addressed because not only it is associated with increased risk of pneumonia but it also incurs unnecessary cost to the patient and the healthcare system [4,17].

The causes of over-prescribing of ICS are multifactorial. Difficulties in distinguishing between asthma and COPD or co-existing of both conditions could lead to prescribers to prefer inhaled therapy that is effective in both asthma and COPD if diagnosis is not based on spirometry. Physicians may evaluate disease severity based on their clinical judgement of symptoms rather than spirometry results as recommended by COPD-X guideline. Patient's history of previous COPD exacerbations is an important consideration for appropriate use of ICS, however this information may not be readily available to physicians at the time of prescribing. Therefore, physicians may be more willing to prescribe ICS outside of guideline recommendations when confronted by symptomatic patients already on maximum therapy of bronchodilators. Additionally, all COPD therapies including ICS are readily subsidized by the Australian pharmaceutical benefit scheme making them easy to access for most patients. Given the above findings, physicians may need to be more vigilant and avoid over-prescribing of combination ICS therapy in COPD patients with no repeated exacerbations or overlapping asthma.

The percentage of patients treated in accordance with the COPD-X guidelines was slightly higher in those managed by the respiratory team compared to non-respiratory team ( $56 \%$ vs $50 \%$, $\mathrm{p}=0.389$ ), however the difference did not reach statistical significance with univariate analysis. Over-treatment was less likely in patients managed by the respiratory team in this cohort as shown by multiple regression analysis $(\mathrm{OR}=0.485$ 95\% $\mathrm{CI}(0.258-0.913), \mathrm{p}<0.05)$. This could be due to an increased 
awareness with respiratory physicians regarding the widespread overprescribing of ICS in COPD patients and the risks associated with the overuse of ICS.

Our study had multiple limitations. This study was retrospective in nature and data was extracted based on medical records from a single centre. There may be incomplete history of patients' previous COPD exacerbations if those patients presented to primary care practitioners or other hospitals previously. In this study, the appropriateness of COPD therapy was compared against the local COPD guidelines rather than the international GOLD guideline. The COPD-X guidelines used $\mathrm{FEV}_{1}$ for disease staging and treatment recommendations, whereas the GOLD guidelines have incorporated patient-reported outcome of dyspnoea to determine therapy since the 2011 update. However, the new classification system in the GOLD guidelines had not been proven to be superior to spirometry grading in terms of mortality prediction or improvement in health outcomes [18-20]. Also the reliability of dyspnoea assessment during an acute exacerbation of COPD is questionable. Therefore the recommendations from COPD-X guideline were followed in our study to assess therapy appropriateness based on spirometry grading. Despite the use of different parameters for disease assessment, the treatment recommendations in both guidelines are mostly aligned $[1,3]$.

\section{Conclusion}

This study identified both under-treatment and over-treatment patterns in patients admitted to hospital for management of COPD. A slightly better compliance to COPD prescribing guidelines among respiratory teams was evident in this audit although the results were not statically significant. Our study highlighted several factors affecting the prescribing of appropriate maintenance COPD treatments, such as history of asthma or previous COPD exacerbations. Further studies are needed to implement education interventions to improve guideline awareness and evaluate the associated impact on guideline adherence rate and patient outcomes.

\section{Acknowledgments}

The authors would like to thank Lilian Vo for her assistance with data collection. This study was not funded by any grants.

\section{References}

1. Lung Foundation Australia. Stepwise Management of Stable COPD [Internet]. Queensland: Lung Foundation Australia; 2017 [updated 2017 August cited 2017 Oct 28]. [Available from: https://lungfoundation.com.au/wp-content/uploads/2017/10/ LFA-Stepwise-Management-of-COPD_0817_WEB.pdf]

2. Mckenzie DK, Abramson M, Crockett AJ, Ta M, George J (2011) Management of chronic obstructive pulmonary disease in Australia after the publication of national guidelines. Int Med J 41: 263-270. [Crossref]

3. Global Initiatives for Chronic Obstructive Lung Disease. Global strategy for the diagnosis, management, and prevention of Chronic Obstructive Pulmonary Disease (2017 report). [Available from: https://goldcopd.org/gold-2017-global-strategydiagnosis-management-prevention-copd]

4. White P, Thornton H, Pinnock H, Georgopoulou S, Booth H (2013) Overtreatment of COPD with Inhaled Corticosteroids - Implications for Safety and Costs: CrossSectional Observational Study. PLos One 8: e75221. [Crossref]
5. Price D, West D, Brusselle G, Gruffydd-Jones K, Jones R, et al. (2014) Management of COPD in the UK primary-care setting: an analysis of real-life prescribing patterns. Int J COPD 9: 889-905. [Crossref]

6. Foda H, Brehm A, Goldsteen K, Edelman N (2017) Inverse relationship between nonadherence to original GOLD treatment guidelines and exacerbations of COPD. Int J COPD 12: 209-214. [Crossref]

7. Miravitlles M, Sicras A, Crespo C, Cuesta M, Brosa M, et al. (2013) Costs of chronic obstructive pulmonary disease in relation to compliance with guidelines: a study in the primary care setting. Ther Adv Respir Dis 7: 139-150. [Crossref]

8. Seys D, Bruyneel L, Decramer M, Lodewijickx C, Panella M, et al. (2017) An International Study of Adherence to Guidelines for Patients Hospitalised with a COPD Exacerbation. COPD 14: 156-163. [Crossref]

9. Pretto JJ, McDonald VM, Wark PAB, Hensley MJ (2012) Multicentre audit of inpatient management of acute exacerbations of chronic obstructive pulmonary disease: comparison with clinical guidelines. Intern Med J 42: 380-387. [Crossref]

10. Pothirat C, Liwsrisakun C, Bumroongkit C, Deesomchok A, Theerakitttikul T, et al. (2015) Comparative study on health care utilization and hospital outcomes of severe acute exacerbation of chronic obstructive pulmonary disease managed by pulmonologist vs internists. Int J Chron Obstruct Pulmon Dis 10: 759-766. [Crossref]

11. Gershon AS, Macdonald EM, Luo J, Austin PC, Gupta S, et al. (2017) Concomitant pulmonologist and primary care for chronic obstructive pulmonary disease: a population study. Fam Pract 34: 708-16. [Crossref]

12. AIHW. Chronic obstructive pulmonary disease: Who gets COPD? Canberra; Australian Institute of Health and Welfare. 2017. [updated on 2017 Dec 22 cited 2017 Oct 28]. [Available from: https://www.aihw.gov.au/reports/asthma-other-chronic-respiratoryconditions/copd-chronic-obstructive-pulmonary-disease/]

13. AIHW. Admitted patient care 2015-16: Australian hospital statistics. Canberra: Australian Institute of Health and Welfare. 2017. [updated on 2017 May 17 cited 2017 Oct 28]. [https://www.aihw.gov.au/reports/hospitals/ahs-2015-16-admitted-patientcare/contents/table-of-contents]

14. Sen E, Guclu SZ, Kibar I, Ocal U, Yilmaz V, et al. (2015) Adherence to GOLD guideline treatment recommendations among pulmonologists in Turkey. Int J Chron Obstruct Pulmon Dis 10: 2657-2663. [Crossref]

15. Jones RC, Dickson-Spillmann M, Mather MJ, Marks D, Shackell BS (2008) Accuracy of diagnostic registers and management of chronic obstructive pulmonary disease: the Devon primary care audit. Respir Res 9: 62. [Crossref]

16. Bourbeau J, Sebaldt RJ, Day A, Bouchard J, Kaplan A, et al. (2008) Practice patterns in the management of chronic obstructive pulmonary disease in primary practice: the CAGE study. Can Respir J 15: 13-19. [Crossref]

17. Tricco AC, Strifler L, Veroniki A, Yazdi, F, khan P A, et al. (2015) Comparative safety and effectiveness of long-acting inhaled agents for treating chronic obstructive pulmonary disease: a systemic review and network meta-analysis. BMJ Open 5: e009183. [Crossref]

18. Soriano JB, Lamprecht B, Ramirez AS, Martinez-Camblor P, Kaiser B, et al. (2015) Mortality prediction in chronic obstructive pulmonary disease comparing the GOLD 2007 and 2011 staging systems: a pooled analysis of individual patient data. Lancet Respir Med 3: 443-450. [Crossref]

19. Goossens LM, Lelmer I, Metzdorf N, Becker K, Rutten-van Molken MP (2014) Does the 2013 GOLD classification improve the ability to predict lung function decline, exacerbations and mortality: a post-hoc analysis of 4-year UPLIFT trial. BMC Pulm Med 2014; 14:163. [Crossref]

20. Kim J, Yoon HI, Oh YM, Lim SY, Lee J, et al. (2015) Lung function decline rates according to GOLD group in patients with chronic obstructive pulmonary disease. Int $J$ Chron Obstruct Pulmon Dis 10: 1819-27. [Crossref]

Copyright: (C2019 Khalil V. This is an open-access article distributed under the terms of the Creative Commons Attribution License, which permits unrestricted use, distribution, and reproduction in any medium, provided the original author and source are credited. 